\title{
Connectome of the Suprachiasmatic Nucleus: New Evidence of the Core-Shell Relationship
}

\author{
Shruti Varadarajan, ${ }^{1}$ Mary Tajiri, ${ }^{1}$ Rashi Jain, ${ }^{1}$ Rebecca Holt, ${ }^{1}$ Qanetha Ahmed, ${ }^{1}$ Joseph LeSauter, ${ }^{1}$ and
} (1) Rae Silver ${ }^{1,2}$

https://doi.org/10.1523/ENEURO.0205-18.2018

${ }^{1}$ Department of Psychology, Barnard College, New York, NY 10027, and ${ }^{2}$ Departments of Psychology, Columbia University, New York, NY, 10027 and of Pathology and Cell Biology, Columbia University, New York, NY 10032

\section{Visual Abstract}
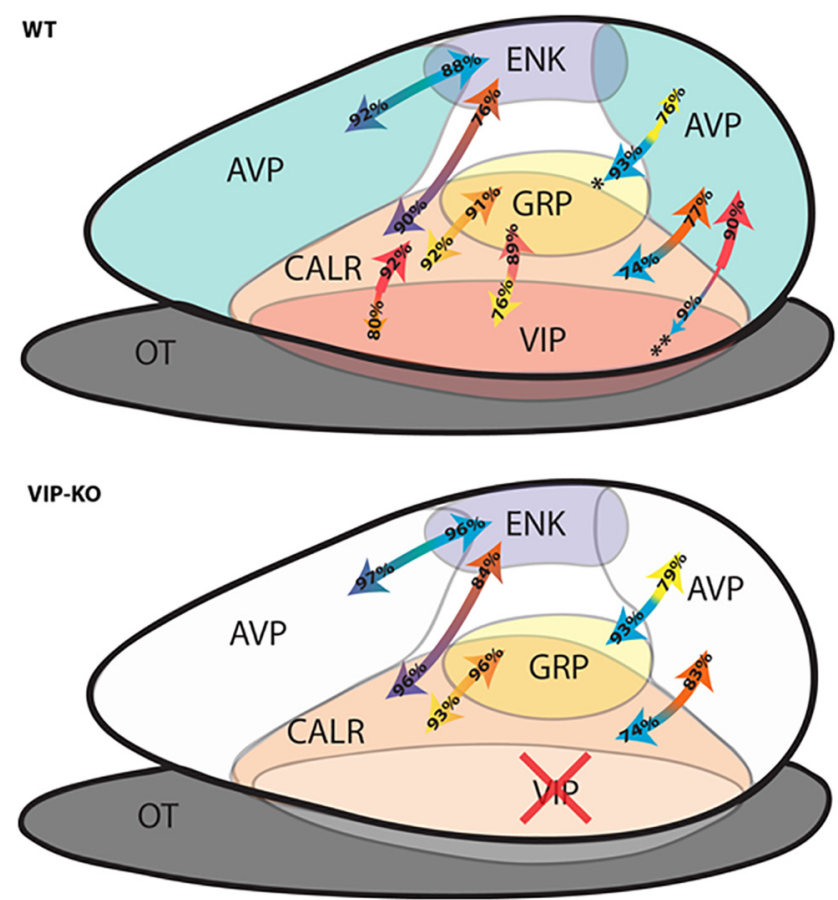

\section{Significance Statement}

The suprachiasmatic nucleus (SCN) brain clock bears $\sim 20,000$ neurons of many peptidergic types. Numerous studies have focused broadly on the core [vasoactive intestinal polypeptide (VIP)-rich]-to-shell [arginine vasopressin (AVP)-rich] areas, leaving aside questions of interconnections among specific peptidergic neuron types. Here, we describe contacts between AVP, gastrin-releasing peptide (GRP), VIP, met-enkephalin (ENK), and calretinin (CALR) SCN peptidergic phenotypes in wild-type (WT) mice and examine changes to these connections consequent to loss of the key core peptide, VIP. Thus, in the absence of VIP, expression of the shell peptide AVP was reduced. The work delineates interrelationships among specific SCN neurons and highlights a complexity in interpreting the consequences of single gene knock-outs. 
A brain clock, constituted of $\sim 20,000$ peptidergically heterogeneous neurons, is located in the hypothalamic suprachiasmatic nucleus (SCN). While many peptidergic cell types have been identified, little is known about the connections among these neurons in mice. We first sought to identify contacts among major peptidergic cell types in the SCN using triple-label fluorescent immunocytochemistry (ICC). To this end, contacts among vasoactive intestinal polypeptide (VIP), gastrin-releasing peptide (GRP), and calretinin (CALR) cells of the core, and arginine vasopressin (AVP) and met-enkephalin (ENK) cells of the shell were analyzed. Some core-to-shell and shell-to-core communications are specialized. We found that in wild-type (WT) mice, AVP fibers make extremely sparse contacts onto VIP neurons but contacts in the reverse direction are numerous. In contrast, AVP fibers make more contacts onto GRP neurons than conversely. For the other cell types tested, largely reciprocal connections are made. These results point to peptidergic cell type-specific communications between core and shell SCN neurons. To further understand the impact of VIP-to-AVP communication, we next explored the SCN in VIP-deficient mice (VIP-KO). In these animals, AVP expression is markedly reduced in the SCN, but it is not altered in the paraventricular nucleus (PVN) and supraoptic nucleus (SON). Surprisingly, in VIP-KO mice, the number of AVP appositions onto other peptidergic cell types is not different from controls. Colchicine administration, which blocks AVP transport, restored the numbers of AVP neurons in VIP-KO to that of WT littermates. The results indicate that VIP has an important role in modulating AVP expression levels in the SCN in this mouse.

Key words: circadian rhythm; connectome; gastrin-releasing peptide; suprachiasmatic nucleus; vasoactive intestinal polypeptide; vasopressin

\section{Introduction}

It is well established that the suprachiasmatic nucleus ( $\mathrm{SCN}$ ) is a master brain clock, made up of many peptidergic neuronal types, and that the various SCN subregions are characterized by clusters of similar peptidergic cells (Antle and Silver, 2005; Yan et al., 2007). Among the best studied cell types of these SCN subregions are neurons synthetizing arginine vasopressin (AVP) in the shell or dorsal region, and those expressing vasoactive intestinal polypeptide (VIP) in the core or ventral region (Abrahamson and Moore, 2001; Moore et al., 2002; Antle and Silver, 2005). Also found in the shell are met-enkephalin (ENK)expressing neurons and in the core are calretinin (CALR) and gastrin-releasing peptide (GRP)-producing neurons (Silver et al., 1999; Abrahamson and Moore, 2001). Possibly due to the small size of SCN neurons and its fine afferent and efferent fibers, there is relatively little known about the connectivity among these diverse neuronal cell types and how these might be altered in arrhythmic mutant animals.

Received May 23, 2018; accepted September 7, 2018; First published September 17, 2018.

The authors declare no competing financial interests.

Author contributions: J.L. and R.S. designed research; S.V., M.T., R.J., R.H., and Q.A. performed research; S.V., M.T., R.J., and J.L. analyzed data; J.L. and R.S. wrote the paper.

This work was supported by National Science Foundation Grants 1256105 and 1749500 (to R.S.).

Acknowledgments: We thank Dr. L. Kriegsfeld (University of California, Berkeley) and Dr. C. S. Colwell (University of California, Los Angeles) for their gift of VIP-KO mutant mice. We also thank Kania Rimu (Barnard College) for cell counts and Anna Li (Barnard College) for illustrations.

Correspondence should be addressed to Rae Silver, Department of Psychology, Mail Code 5501, Columbia University, 1190 Amsterdam Avenue, New York, NY 10027, E-mail: qr@columbia.edu.

https://doi.org/10.1523/ENEURO.0205-18.2018

Copyright (C) 2018 Varadarajan et al.

This is an open-access article distributed under the terms of the Creative Commons Attribution 4.0 International license, which permits unrestricted use, distribution and reproduction in any medium provided that the original work is properly attributed.

\section{Importance of networks}

As for other brain regions, it is generally accepted that the connectivity and characteristics of its neurons play an important role in the SCN functional specialization. Although individual SCN neurons are autonomous oscillators, they must function within a network to generate circadian rhythmicity within the nucleus (Welsh et al., 2010). There is limited information available on connectivity among SCN neurons. Early studies in rat using Golgi and Nissl staining in light and electron microscopic work demonstrated that the axons and dendrites of the greatest majority of its neurons terminate within the SCN (Güldner, 1976, 1984; van den Pol, 1980; Güldner, 1983; van den Pol and Tsujimoto, 1985; Klein et al., 1991). Güldner (1976) estimated that each SCN neuron made 300-1000 synaptic contacts. Subsequent work confirmed this assessment and estimated that within the SCN, individual neurons make as many as 1000 synapses (Moore and Bernstein, 1989). There is evidence of substantial communication within neurons of a specific cell type in that boutons immunoreactive for AVP synapse onto AVP containing dendrites and similarly, boutons containing GRP synapse onto GRP cells (van den Pol and Gorcs, 1986). Taken together, the weight of evidence indicates that network organization and communication among neurons, is key to the functioning of the brain clock, although little work has been done on the connections among SCN cell types.

\section{Connections of SCN cell types}

There have been a few studies of contacts among SCN peptidergic cell types in the rat and hamster but none in mice, to our knowledge. In rats, using double-label immunochemistry, reciprocal appositions have been described between neurons bearing the following peptides: AVP and VIP (Ibata et al., 1993; Jacomy et al., 1999); AVP, VIP, and GRP (Romijn et al., 1997).

In hamsters, injection of tracers into the SCN indicates that the dorsal and medial regions project densely to most of the nucleus, but not to the core region, which had been 
identified by calbindin (CalB) neurons (Kriegsfeld et al., 2004). Interconnections among CalB and other peptidergic cells of the SCN have been examined using epiand confocal microscopy and intra-SCN tract tracing (LeSauter et al., 2002, 2009).

Dynamic aspects of network organization have also been described. There is a rhythm in CalB expression in fibers, with many appositions seen between GRP and AVP at zeitgeber time (ZT)14 but exceedingly few at ZT4 (LeSauter et al., 2009). A similar finding has been reported in rats where more CALR fibers are typically seen at ZT14 than at ZT2 (Moore, 2016). To explore the intra-SCN network in which GRP neurons participate in more detail, individual GRP neurons bearing green fluorescent protein (GFP) were filled with biocytin tracer (Drouyer et al., 2010). These neurons form a dense network of local circuits within the core, revealed by appositions on other GFPcontaining cells and by the presence of dye-coupled cells. Dendrites and axons of GRP cells make appositions on AVP neurons, whereas adjacent biocytin tracer-filled, non-GRP cells have a less extensive fiber network, largely confined to the region of GRP-bearing cells. This work in rats and hamsters points to the highly specialized connectome of the SCN and to its temporal dynamics.

\section{Importance of core and shell communication}

The anatomic division of SCN into core and shell regions, based on the location of AVP and VIP-containing neurons aligns well with its functional organization. VPAC2, the receptor for VIP, is abundant in the SCN (Cagampang et al., 1998) and is essential in maintaining intercellular and behavioral rhythmicity in the SCN. Mice bearing a null mutation of the VPAC2 receptor cannot sustain normal circadian activity rhythms (Harmar et al., 2002; Piggins and Cutler, 2003; Maywood et al., 2006). In accord with the implications of this finding, mice lacking VIP in the SCN have abnormal circadian activity, impaired cellular rhythmicity, and reduced synchrony among neurons (Aton et al., 2005; Brown et al., 2007). In arrhythmic mice lacking essential components of the circadian transcription-translation feedback loop, the introduction of VIP signaling is sufficient to coordinate gene expression and maintain rhythmicity (Maywood et al., 2011). Such findings support the hypothesis that VIP originating in the core SCN, acting through its receptor, is crucial for maintaining rhythmicity.

The present study was designed to examine the connectome of the mouse SCN, as has previously been done in rats and hamsters. Given the importance of VIP and AVP in regulating circadian rhythmicity, a second goal was to assess changes in the network organization consequent to the loss of VIP. Thus, we examined sagittal and coronal sections of the SCN and used triple-label immunocytochemistry (ICC) and confocal microscopy, to examine wild-type (WT) and VIP-KO mice. We stained for neurons of the core, namely GRP, VIP, and CALR as well as those of the shell, specifically AVP and ENK. The contacts between various peptidergic types were quantified by determining the number of appositions between fibers of one peptidergic type onto the cell body of an- other. The results present a first analysis of the mouse SCN connectome network that leads to the generation of the circadian rhythm. The results also describe a vital role for VIP in determining AVP expression levels.

\section{Materials and Methods}

\section{Animals and housing}

Two genotypes of male animals were used in this study. C57BL/6NJ mice (RRID:IMSR_JAX:005304) were obtained at 6 weeks of age from The Jackson Laboratory. VIP/Peptide Histidine Isoleucine (PHI) $+/+(\mathrm{WT})$, heterozygous VIP/PHI \pm and knock-out VIP/PHI-/- (VIP-KO) mice were derived from breeding pairs of heterozygous VIP/ $\mathrm{PHI} \pm$ mice provided by Dr. C. S. Colwell (University of California, Los Angeles). These mice had been raised on a C57BL/6 background (Colwell et al., 2003).

Animals were housed in translucent propylene cages $(48 \times 27 \times 20 \mathrm{~cm})$ and provided with ad libitum access to food and water. They were maintained in a 12/12 h light/ dark cycle at a room temperature of $21^{\circ} \mathrm{C}$. Mice were sacrificed at ZT14, at three to four months of age. This time was selected because previous studies indicated a substantial time of day effect of calcium binding proteins on the SCN connectome, with high fiber expression at ZT14 (LeSauter et al., 2009; Moore, 2016). Mice were deeply anesthetized with sodium pentobarbital $(200 \mathrm{mg} /$ $\mathrm{kg}$ ) and perfused intracardially with saline followed by $4 \%$ paraformaldehyde in $0.1 \mathrm{M}$ phosphate buffer, $\mathrm{pH}$ 7.3. All handling of animals was done in accordance with the Institutional Animal Care and Use Committee guidelines of the University.

\section{Antibodies}

The primary antibodies were rabbit polyclonal anti-AVP (\#20069, 1:5000, Immunostar, RRID:AB_572219); goat polyclonal anti-NP (sc-27093, Santa Cruz Biotechnology, RRID: AB_2061964); rabbit polyclonal anti-VIP (\#20077, 1:5000, Immunostar, RRID:AB_572270), rabbit polyclonal anti-GRP (\#20073, 1:2000, Immunostar, RRID:AB_572221), or rabbit polyclonal anti-ENK (\#20065, 1:7500, Immunostar, RRID: AB_572250); goat polyclonal anti-CALR (\#AB1550, 1:2000, Millipore Bioscience Research Reagents, RRID:AB_90764). Guinea pig polyclonal anti-AVP and anti-VIP (T-5048, RRID: AB_518680; and T-5030, RRID:AB_518690, Peninsula Laboratories) were also used in a few experimental runs with good results, similar to those with the rabbit antibodies and some sections were double-labeled with GRP-VIP using the anti-VIP made in guinea pig. New batches of the antibodies, however, gave very poor results and were not used further. In instances where all available primary antibodies were made in rabbit, we were not able to double-label the sections.

\section{Immunocytochemistry (ICC)}

Brains were postfixed for $24 \mathrm{~h}$ at $4^{\circ} \mathrm{C}$ and then cryoprotected in $20 \%$ sucrose in $0.1 \mathrm{M}$ phosphate buffer (PB) overnight. Coronal or sagittal sections $(50 \mu \mathrm{m})$ were cut on a cryostat. Both single- and triple-label ICC was performed. We note that coronal sections are more familiar to students of the SCN than are sagittal sections. That said, 
A
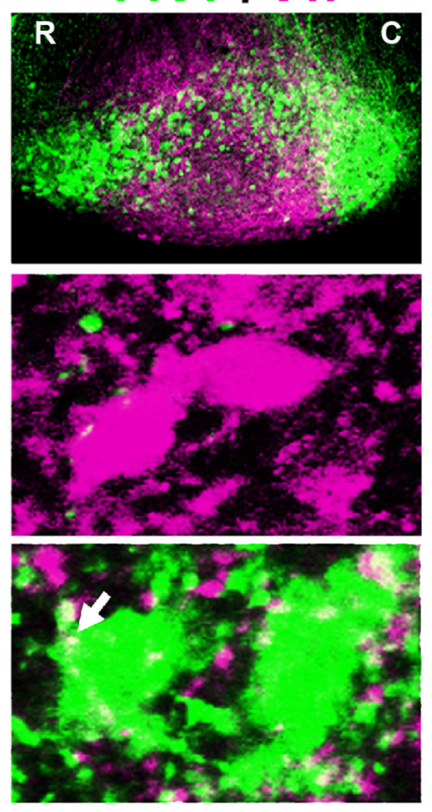

\section{B VIP/GRP}
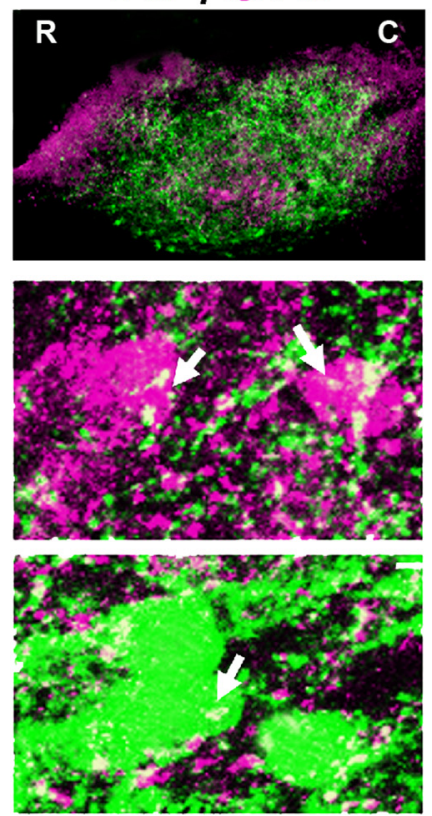

AVP/GRP
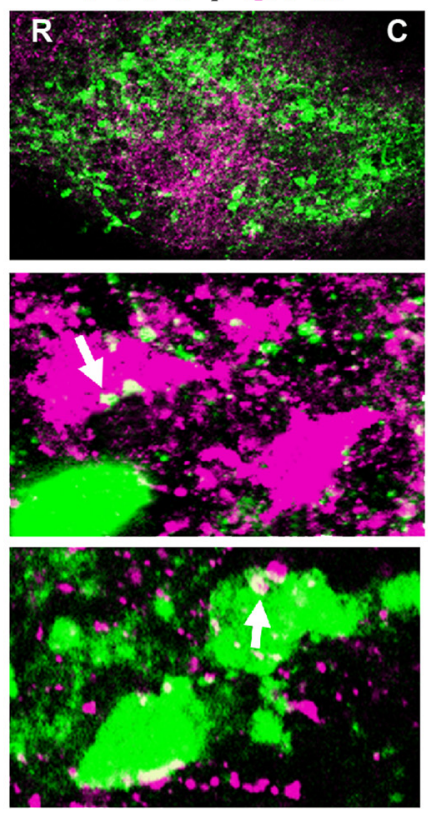

VIP/CALR
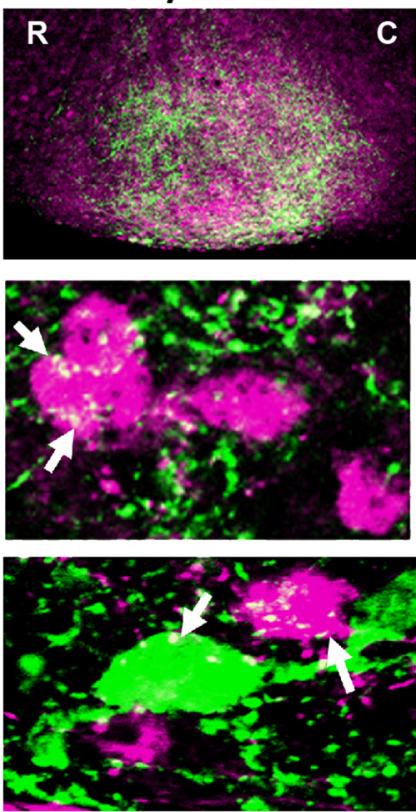

AVP/CALR
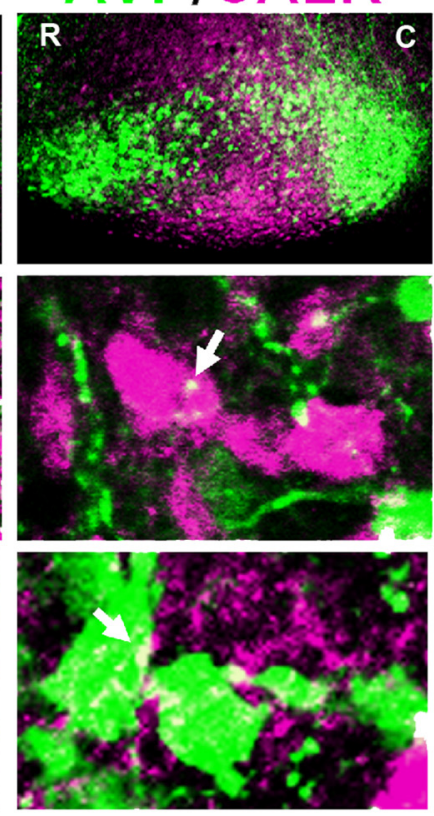

GRP/CALR
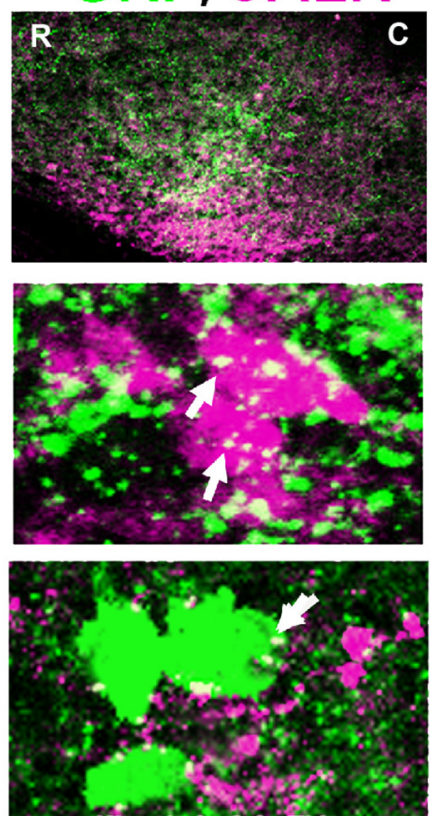

AVP/ENK
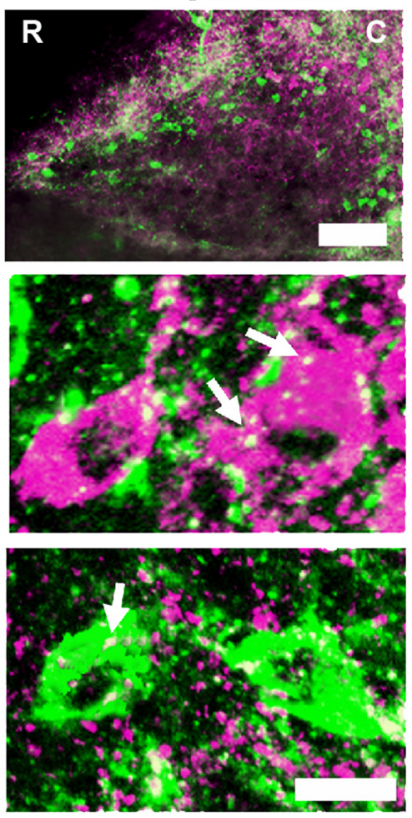

ENK/CALR
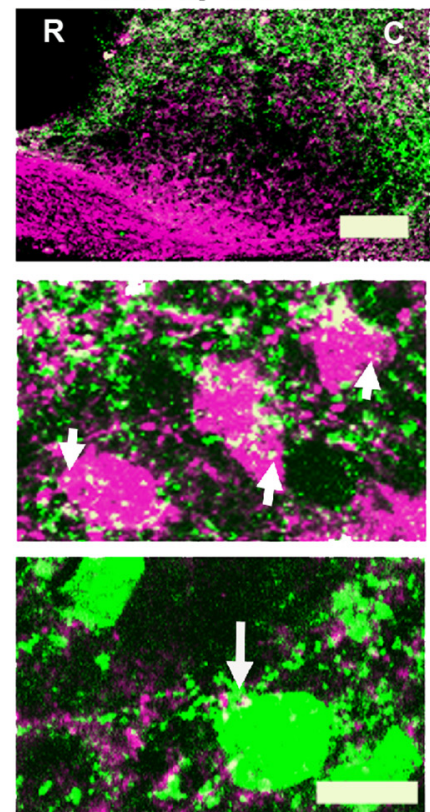

Figure 1. Photomicrographs of neuronal connections in the SCN of WT mice. $\boldsymbol{A}$, The images show the localization of neurons and fibers revealing AVP contacts onto VIP, GRP, CALR, and ENK neurons. $\boldsymbol{B}$, The images show the relationship between VIP and GRP, CALR and CALR with GRP and ENK. In both panels, the first row shows confocal images of the SCN as a whole to visualize the location of each of the cell types (z-axis: $8 \mu \mathrm{m}$; scale bar $=100 \mu \mathrm{m}$; R, rostral SCN; C, caudal SCN). The images in the second and third rows have been overexposed to optimize visualization of appositions of fibers onto neurons (arrows) for each of the peptides in the first row $(z$-axis $=2 \mu \mathrm{m}$; scale bars $=10 \mu \mathrm{m})$.

in the coronal view, the connections along the rostralcaudal plane are severed. Because there is evidence that indicates the importance of the network along the rostrocaudal axis (Hazlerigg et al., 2005; Yan and Silver, 2008; Sosniyenko et al., 2009; Buijink et al., 2016), we used sagittal sections to investigate the network in this plane. We use coronal sections as well to enable reviewers to relate familiar coronal views of the nucleus to the less familiar sagittal view.

For single label immunofluorescence of brain sections were washed in $0.1 \mathrm{M}$ PB with $0.1 \%$ Triton X-100 $(0.1 \%$ PBT; Sigma-Aldrich), incubated in normal donkey serum (catalog \#017-000-121 RRID:AB_2337258; Jackson ImmunoResearch) in $0.3 \%$ PBT for $1 \mathrm{~h}$, and then incubated 

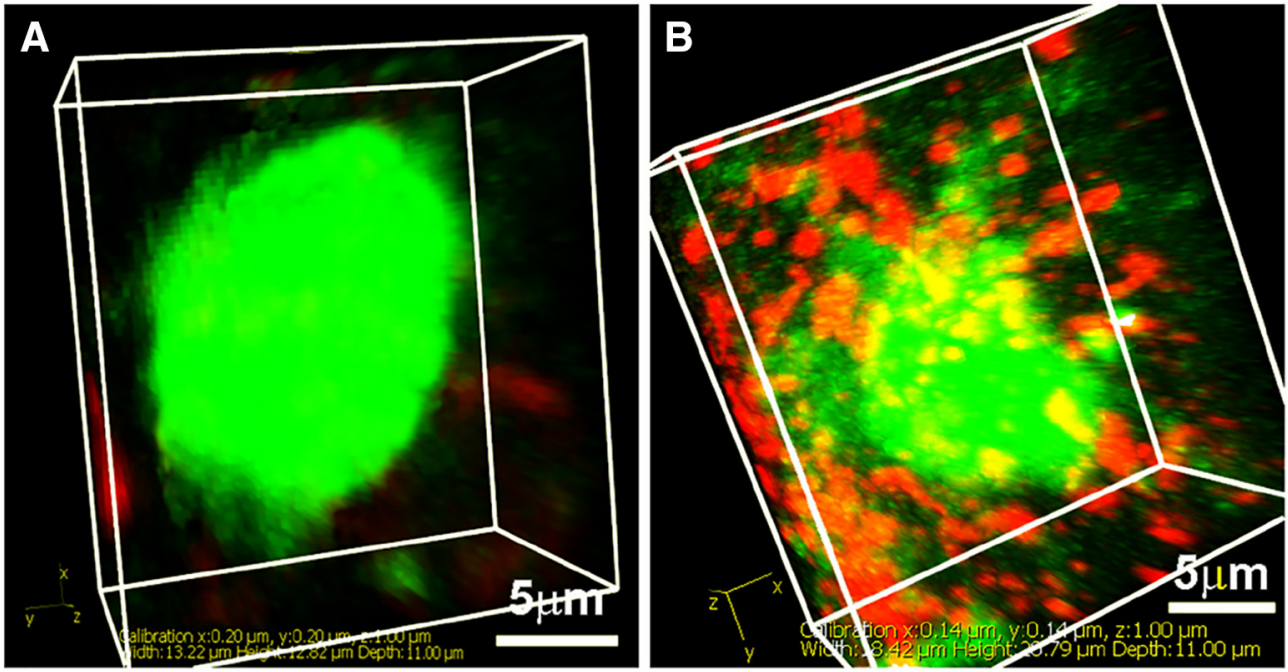

Figure 2. 3D projection of images, each made from confocal stacks of 11 images of serial $1-\mu \mathrm{m}$ slices, shows the range of appositions observed. A, Image shows an example of an AVP neuron (green) lacking appositions from CALR neurons (red). B, Image shows an AVP neuron (green) bearing numerous VIP (red) appositions.

in rabbit anti-AVP at $4^{\circ} \mathrm{C}$ for $48 \mathrm{~h}$. The sections were then washed in $0.1 \%$ PBT incubated in donkey anti rabbit secondary antibody conjugated to Cy2 fluorescent chromogen (RRID:AB_2340612, Jackson ImmunoResearch). Finally, sections were washed with $0.1 \mathrm{M} \mathrm{PB}$, mounted, dehydrated in a series of $50-100 \%$ ethanol, and coverslipped with Krystalon (EMD Chemicals) and cover glass No. 1 (Fisher Scientific; catalog \#12-544-18).

For triple-label immunofluorescence, sections were incubated in three primary antibodies raised in different species. Secondary antibodies were a mixture of Cy2 donkey anti-guinea pig (RRID:AB_2340467), Cy3 donkey anti-rabbit (RRID:AB_2340606), and Cy5 donkey anti-goat (RRID:AB_2340415) fluorescent chromogens (Jackson ImmunoResearch). Sections were washed, dehydrated, and coverslipped as above.

\section{Comparison of AVP staining in VIP-KO and WT}

AVP cell counts in SCN, supraoptic nucleus (SON), and paraventricular nucleus (PVN), in WT and VIP-KO littermates, were studied in simultaneous immunostaining runs, using $50-\mu \mathrm{m}$ coronal sections. For AVP cell counts in SCN of WT and colchicine-treated VIP-KO littermates, $50-\mu \mathrm{m}$ sagittal sections were used. Photomicrographs of these areas were captured with a Nikon Eclipse E800 microscope (Nikon) equipped with a cooled CCD camera (Retiga Exi; Q-Imaging), using Q-capture software (RRID: SCR_014432, Q-Imaging) with the excitation wavelengths $480 \pm 20 \mathrm{~nm}$ for Cy2. Images were stored as TIFF files with a $1392 \times 1040$-pixel array and then imported into Adobe Photoshop CS6 (Adobe Systems, Inc., RRID: SCR_014199). Counts were done independently by two researchers blind to the experimental conditions on three sections for each region with six mice/group and are reported as cell number/brain section. Inter-observer reliability was $\geq 93 \%$.

AVP cell counts in WT and VIP-KO littermates were studied in a series of confocal images using ImageJ (Na- tional Institutes of Health; RRID:SCR_003070). The perimeter was measured on 1- $\mu \mathrm{m}$ optical sections in the largest extent of the neuron where a distinct nucleus was seen. The area through this plane was calculated from the perimeter.

\section{Appositions and colocalization \\ Confocal microscopy}

Each triple-labeled section containing the SCN was observed under a Zeiss Axiovert 200 MOT fluorescence microscope with a Zeiss LSM 510 laser scanning confocal attachment (Carl Zeiss). The sections were excited with argon-krypton, argon, and helium-neon lasers using the excitation wavelengths of $488 \mathrm{~nm}$ for Cy2, $543 \mathrm{~nm}$ for Cy3, and $633 \mathrm{~nm}$ for Cy5. Each laser was excited sequentially to avoid cross talk between the three wavelengths.

\section{Determination of appositions}

For visualization of the entire SCN, images were collected with a $20 \times$ objective as $8-\mu \mathrm{m}$ multitract optical sections. For analysis of contacts among various peptidergic cell types, images were collected with a $63 \times$ objective (in Fig. 1, but not for the data analysis, images were overexposed to enhance visualization of the appositions). SCN neurons were examined through their entirety in $1-\mu \mathrm{m}$ increments (z-axis), using the LSM 3.95 software (Carl Zeiss). Each neuronal cell body was examined to evaluate whether it bore zero, one to two, or more than or equal to three or more appositions, as in prior work (Jacomy et al., 1999; LeSauter et al., 2009). In addition, the total number of appositions made by AVP onto GRP, CALR, and ENK was assessed. There are caveats to the present methods of evaluating contacts, including (1) dendrites and axons cannot be differentiated, (2) synapses cannot be evaluated and (3) over or underestimation of the number of appositions due to ICC procedure, or (4) to missing fibers cut during sectioning, may occur as previously acknowledged (LeSauter et al., 2009). These 


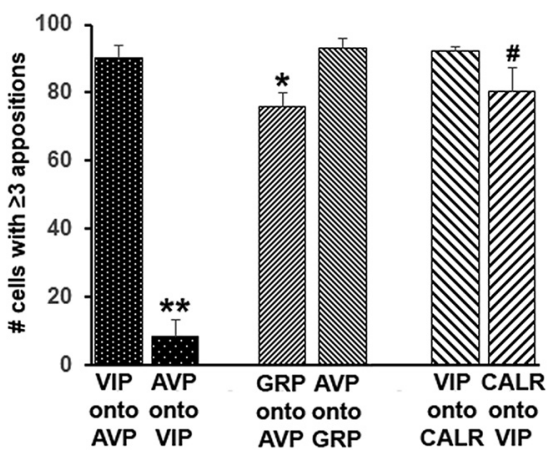

Figure. 3. Number of neurons receiving more than or equal to three appositions. Here, instances of statistically significant differences between contacts made and received are shown, while Table 1 indicates statistical analysis for all appositions examined; $* * p<0.001, * p=0.02 ; \# p=0.06$.

do not affect the comparisons germane to the present study.

\section{AVP in VIP-KO mice}

The number of AVP neurons were compared in VIP-KO colchicine injected, and WT littermates ( $N=6$ /group). VIP-KO mice were anesthetized, by intraperitoneal injection of $60 \mathrm{mg} / \mathrm{kg}$ ketamine and $5 \mathrm{mg} / \mathrm{kg}$ xylazine, placed into the stereotaxic apparatus (David Kopf Instruments), and prepared for aseptic surgery. A 10- $\mu$ l Hamilton syringe (Hamilton) was used to inject $2 \mu \mathrm{l}$ of colchicine (10 $\mu \mathrm{g} / \mu \mathrm{l}$ in $0.9 \%$ saline; Sigma) in the lateral ventricle of VIP-KO animals and they were perfused $72 \mathrm{~h}$ later. Stereotaxic coordinates relative to bregma were: flat skull, anteroposterior, $+1 \mathrm{~mm}$; mediolateral, $+0.7 \mathrm{~mm}$; dorsoventral, $-3.0 \mathrm{~mm}$ from the top of the skull. Sagittal sections from VIP-KO and WT controls were stained for AVP and cell counts were done as above with $90.3 \%$ interobserver agreement.

\section{Determination of colocalization}

To determine the colocalization of two peptides, neurons were examined in confocal scans and were considered double-labeled when coexpression was seen in at least three consecutive $1-\mu \mathrm{m}$ scans.

\section{Statistical analysis}

One-way ANOVA followed by Tukey's post hoc test was used to compare the number of appositions made by each peptidergic cell type onto other peptidergic cell types (Fig. 4). Two-way ANOVA followed by Tukey's post hoc test was used to compare the number of AVP cells in SCN, SON, and PVN of WT and VIP-KO littermate mice (Fig. 6), and to compare the number of AVP appositions onto other cell types in WT and VIP-KO mice (Fig. 7; Table 4); $t$ tests were used for all other comparisons. All analyses were done using SigmaStat 2.03 (RRID: SCR_010285, SPSS Inc.).

\section{Results}

\section{Appositions between peptidergic cell types in the SCN of WT mice}

Contacts between peptidergic neuronal cell types were examined in WT mice, with the goal of determining
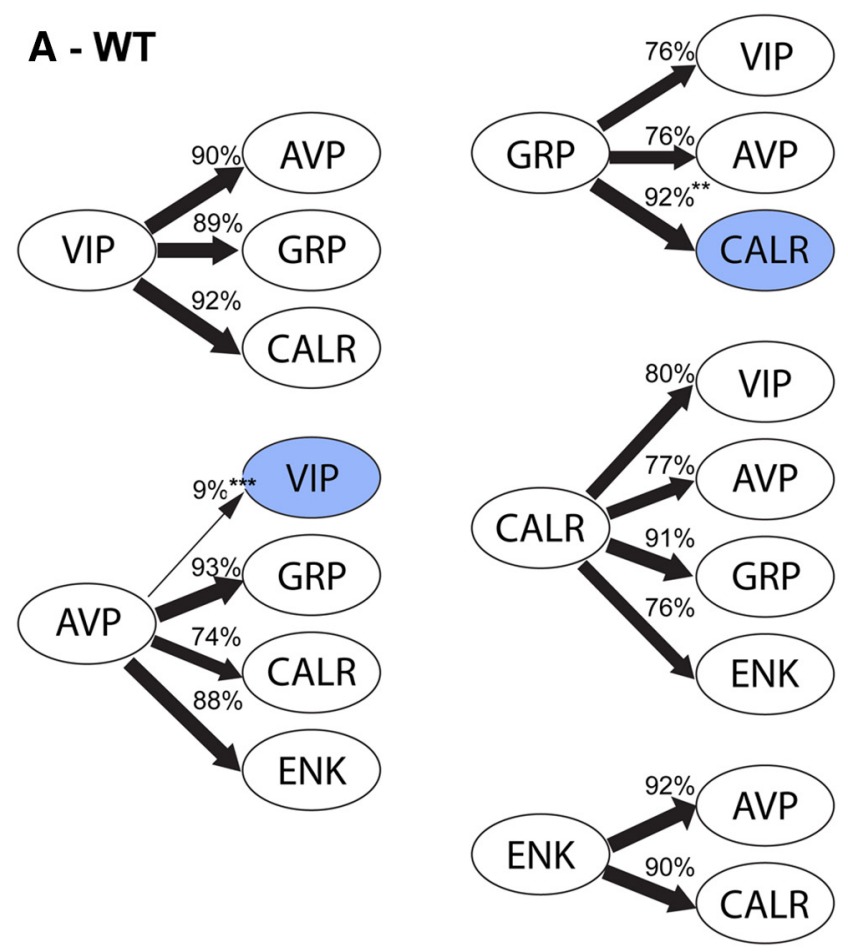

\section{B - VIP-KO}
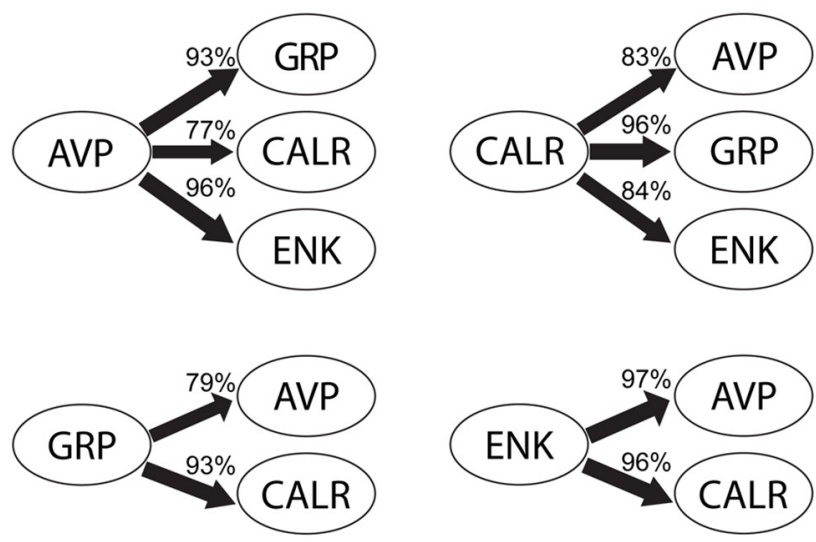

Figure 4. Schematic representations of the connections between peptidergic neuronal types. The numbers and the arrow thickness indicate the proportion of cells receiving more than or equal to three appositions (statistics in Tables 2, 3). $\boldsymbol{A}$, In WT mice, there was a preferential unilateral direction of communication between AVP-VIP and GRP-CALR (blue). While the other connections indicated are all reciprocal, there are few AVP to VIP contacts and more GRP to CALR contacts than the converse $(* * * p<0.001, * * p=0.008)$. $\boldsymbol{B}$, In contrast to WT mice, in VIP-KO mice, there was no evidence of preferential direction of communication between peptidergic cell types.

whether appositions were reciprocal or not between specific cell types. The appositions made by each peptidergic neuron type onto the others were scored, where suitable antibodies were available. Low-power images of the entire SCN show the distribution of each peptide in neurons and fibers in sagittal sections of the SCN (Fig. 1A,B, top rows). The results indicate that AVP neurons are distributed throughout the shell and AVP fibers extend through- 
Table 1. Percentage of neurons receiving appositions from other neuronal cell types per WT mouse (mean \pm SEM)

\begin{tabular}{|c|c|c|c|c|c|c|c|}
\hline Cell type & $\begin{array}{l}\% \text { cells with } \\
\geq 3 \text { appositions }\end{array}$ & $\begin{array}{l}\% \text { cells with } \\
1-2 \text { appositions }\end{array}$ & $\begin{array}{l}\% \text { cells with } \\
0 \text { appositions }\end{array}$ & \# cells & \# animals & $t$ test & $p$ value \\
\hline AVP to VIP & $8.5 \pm 4.9$ & $19.5 \pm 7.7$ & $72.0 \pm 10.8$ & 251 & 6 & & \\
\hline VIP to AVP & $90.3 \pm 3.8$ & $8.9 \pm 3.6$ & $0.8 \pm 0.3$ & 458 & 5 & $t_{(9)}=11.5$ & $<0.001$ \\
\hline AVP to GRP & $93.1 \pm 2.7$ & $6.9 \pm 2.7$ & 0 & 88 & 5 & & \\
\hline GRP to AVP & $75.8 \pm 4.0$ & $17.9 \pm 3.7$ & $6.3 \pm 1.8$ & 446 & 11 & $t_{(14)}=2.63$ & 0.02 \\
\hline AVP to CALR & $73.6 \pm 8.2$ & $7.8 \pm 2.3$ & $18.7 \pm 7.3$ & 1044 & 12 & & \\
\hline CALR to AVP & $77.2 \pm 5.4$ & $6.5 \pm 1$ & $15.9 \pm 5.1$ & 813 & 11 & $t_{(21)}=0.38$ & 0.71 \\
\hline AVP to ENK & $87.8 \pm 4.7$ & $6.6 \pm 2.4$ & $5.6 \pm 3.5$ & 121 & 7 & & \\
\hline ENK to AVP & $91.5 \pm 2.8$ & $7.2 \pm 2.3$ & $1.3 \pm 0.8$ & 381 & 7 & $t_{(12)}=0.63$ & 0.54 \\
\hline VIP to GRP & $88.9 \pm 2.4$ & $7.7 \pm 1.4$ & $3.5 \pm 1.6$ & 61 & 3 & & \\
\hline GRP to VIP & $75.8 \pm 6.6$ & $11.6 \pm 1.7$ & $12.6 \pm 4.9$ & 148 & 3 & $t_{(4)}=1.52$ & 0.20 \\
\hline VIP to CALR & $92.4 \pm 0.9$ & $5.2 \pm 0.4$ & $2.3 \pm 0.8$ & 988 & 8 & & \\
\hline CALR to VIP & $80.3 \pm 7.2$ & $13.5 \pm 8.2$ & $6.2 \pm 1.2$ & 229 & 4 & $t_{(10)}=2.11$ & 0.06 \\
\hline GRP to CALR & $92.3 \pm 2.4$ & $4.0 \pm 1.3$ & $3.7 \pm 1.3$ & 953 & 10 & & \\
\hline CALR to GRP & $90.5 \pm 5.4$ & $7.0 \pm 4.6$ & $2.5 \pm 1.6$ & 99 & 6 & $t_{(14)}=0.43$ & 0.67 \\
\hline ENK to CALR & $89.7 \pm 5.5$ & $7.8 \pm 4.3$ & $2.4 \pm 1.5$ & 432 & 6 & & \\
\hline CALR to ENK & $76.2 \pm 15.4$ & $9.8 \pm 5.4$ & $14.1 \pm 1.1$ & 98 & 5 & $t_{(9)}=0.8$ & 0.44 \\
\hline
\end{tabular}

Statistical analysis tests for preferential direction of communications between neuronal cell types for more than or equal to three appositions.

Table 2. Average percentage of neurons receiving appositions from other neuronal cell types per VIP-KO mouse (mean \pm SEM)

\begin{tabular}{|c|c|c|c|c|c|c|c|}
\hline Cell type & $\begin{array}{l}\% \text { cells with } \\
\geq 3 \text { appositions }\end{array}$ & $\begin{array}{l}\% \text { cells with } \\
1-2 \text { appositions }\end{array}$ & $\begin{array}{l}\% \text { cells with } \\
0 \text { appositions }\end{array}$ & \# cells & \# animals & $t$ test & $p$ value \\
\hline AVP to GRP & $93.0 \pm 5.0$ & $7.0 \pm 5.0$ & 0 & 76 & 5 & & \\
\hline GRP to AVP & $79.0 \pm 10.7$ & $6.5 \pm 5.4$ & $14.6 \pm 7.4$ & 152 & 4 & $t_{(7)}=1.1$ & 0.23 \\
\hline AVP to CALR & $77.0 \pm 9.6$ & $4.3 \pm 2.1$ & $18.7 \pm 7.7$ & 720 & 8 & & \\
\hline CALR to AVP & $82.6 \pm 3.7$ & $5.8 \pm 1.8$ & $11.6 \pm 3.9$ & 549 & 8 & $t_{(14)}=0.5$ & 0.62 \\
\hline AVP to ENK & $96.0 \pm 1.9$ & $3.3 \pm 1.6$ & $1.2 \pm 0.5$ & 218 & 5 & & \\
\hline ENK to AVP & $97.1 \pm 1.7$ & $2.9 \pm 1.7$ & 0 & 222 & 5 & $t_{(8)}=0.6$ & 0.59 \\
\hline $\begin{array}{l}\text { GRP to CALR } \\
\text { CALR to GRP }\end{array}$ & $\begin{array}{l}93.0 \pm 2.5 \\
95.8 \pm 3.9\end{array}$ & $\begin{array}{l}4.0 \pm 1.9 \\
0\end{array}$ & $\begin{array}{l}3.0 \pm 1.8 \\
4.2 \pm 3.9\end{array}$ & $\begin{array}{l}684 \\
109\end{array}$ & $\begin{array}{l}8 \\
8\end{array}$ & $\begin{array}{l}t_{(14)}=0.6 * \\
T_{(8,8)}=51\end{array}$ & $\begin{array}{l}0.58 \\
0.08\end{array}$ \\
\hline $\begin{array}{l}\text { ENK to CALR } \\
\text { CLR to ENK }\end{array}$ & $\begin{array}{l}96.2 \pm 1.7 \\
83.6 \pm 7.9\end{array}$ & $\begin{array}{l}2.7 \pm 1.1 \\
13.6 \pm 6.3\end{array}$ & $\begin{array}{l}1.1 \pm 0.7 \\
2.9 \pm 1.8\end{array}$ & $\begin{array}{l}510 \\
133\end{array}$ & $\begin{array}{l}4 \\
4\end{array}$ & $\begin{array}{c}t_{(6)}=1.4 * \\
T_{(4.4)}=20\end{array}$ & $\begin{array}{l}0.23 \\
0.69\end{array}$ \\
\hline
\end{tabular}

Statistical analysis tests for preferential direction of communications between neuronal cell types for more than or equal to three appositions. * Normality or equal variance failed, Mann-Whitney rank test $(T)$ is shown.

out the shell and the dorsal core. VIP neurons are located in the ventral core while GRP is mostly dorsal to the VIP cells. Both VIP and GRP fibers project throughout the SCN. CALR neurons lie primarily in the ventral SCN and fibers project dorsally throughout the nucleus. ENK neurons are sparsely distributed in the dorsal SCN and the fibers lie throughout the SCN with greatest density in the dorsal region. Figure 1, rows 2, shows examples of appositions of each immunoreactive fiber type studied onto AVP neurons, while Figure 1, rows 3, shows the reciprocal connections.

To quantify the appositions, contacts made by each neuronal type were evaluated using the following categories $\geq 3,1-2,0$ as previously (Jacomy et al., 1999; LeSauter et al., 2002, 2009). Examples of zero and more than or equal to three appositions are shown in Figure 2. The results indicate that all neuronal cell types except one made numerous and reciprocal appositions onto each other. The most impressive exception was the paucity of connections from AVP fibers onto VIP neurons. In con-
Table 3. Difference between WT and VIP-KO in \% neurons receiving more than or equal to three appositions

\begin{tabular}{lll}
\hline Cell type & $t$ test WT vs VIP-KO & $p$ value \\
AVP to GRP & $t_{(8)}=0.02$ & 0.98 \\
GRP to AVP & $t_{(13)}=0.32$ & 0.75 \\
AVP to CALR & $t_{(18)}=0.26$ & 0.80 \\
CALR to AVP & $t_{(17)}=0.68$ & 0.50 \\
AVP to ENK & $t_{(10)}=1.21$ & 0.26 \\
ENK to AVP & $t_{(10)}=1.40$ & 0.19 \\
GRP to CALR & $t_{(16)}=0.02$ & 0.98 \\
CALR to GRP & $t_{(12)}=0.42$ & 0.68 \\
ENK to CALR & $t_{(8)}=0.84$ & 0.43 \\
CALR to ENK & $t_{(7)}=1.02$ & 0.34 \\
\hline
\end{tabular}

Data for each group is shown in Tables 1 (WT) and 2 (VIP-KO).

trast, VIP neurons made numerous contacts onto AVP neurons. There were also significantly more appositions from AVP to GRP than conversely and a marginally greater number of appositions between VIP to CALR than conversely (Fig. 3). 
Hypothalamus - coronal
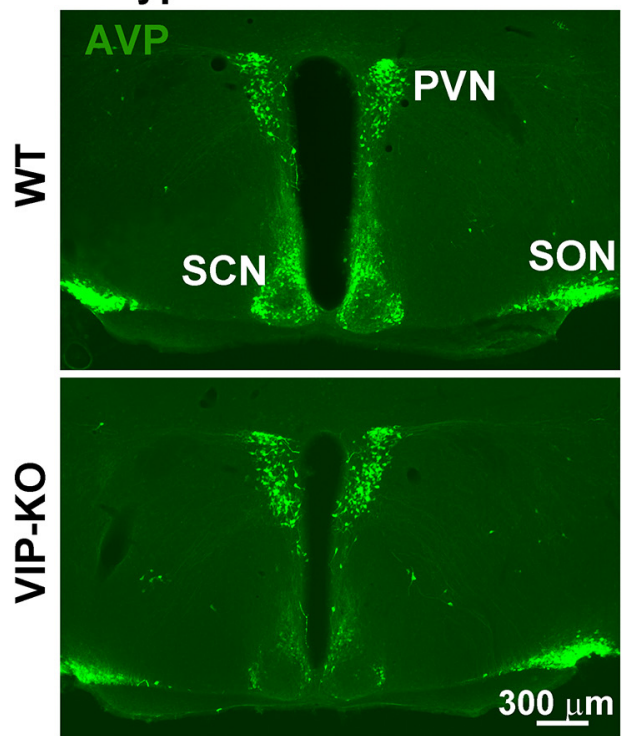

Mid-SCN - coronal
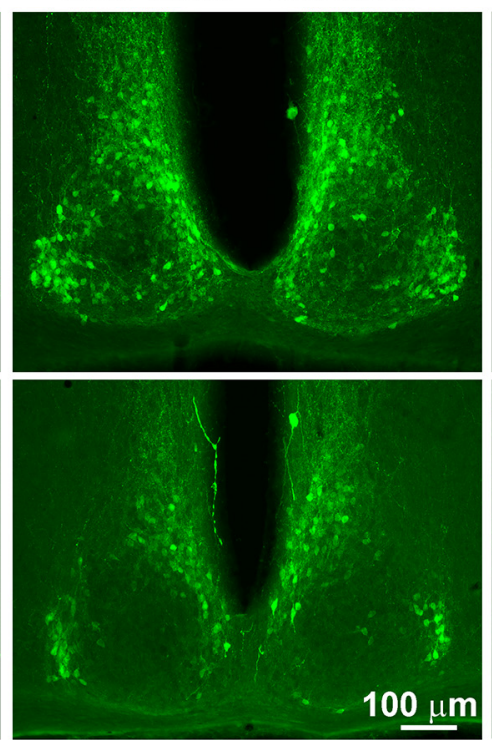

SCN - sagittal
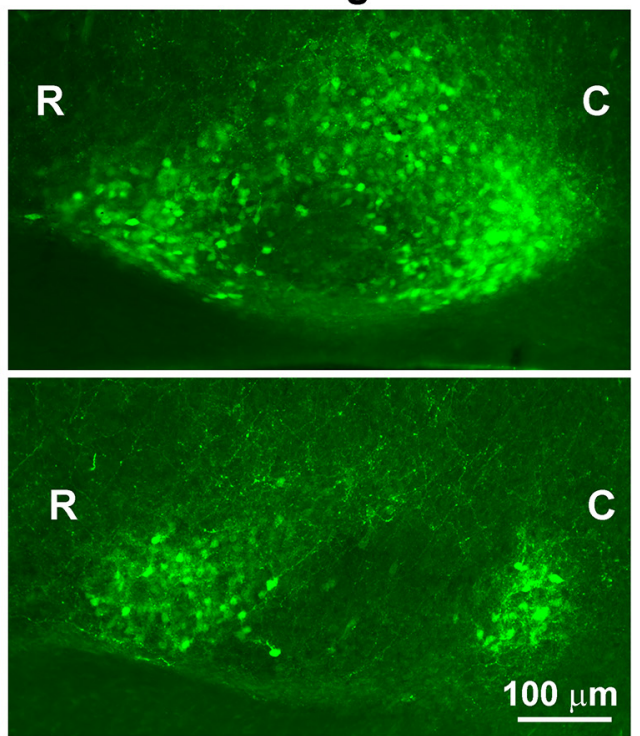

Figure 5. Photomicrographs depict AVP-ir in coronal and sagittal views of the SCN in littermates of WT (top row) and VIP-KO (bottom row) mice tested in the same experimental runs. While AVP expression is similar in PVN and SON of WT and VIP-KO mice, it is reduced in SCN of the mutants ( $R$, rostral; $C$, caudal).

\section{Appositions between peptidergic cell types in the SCN of VIP-KO mice}

Because previous reports indicate that VIP mRNA is reduced at all times of day in VPAC2 mice (Harmar et al., 2002), we sought to determine the state of connections between AVP and other peptidergic cell types in our mice. To our surprise, there were no significant differences in reciprocal connections, detected between WT and VIP-KO mice. In the VIP-KO mouse, AVP to GRP appositions were somewhat more numerous than GRP to AVP, but unlike the WT, this difference was not significant.

We next asked whether a particular peptidergic SCN neuron made selective contacts or communicated equally with all other types [Fig. 4A,B; Tables 1 (WT), 2 (VIP-KO)]. This assessment of appositions shows that AVP fibers contact fewer VIP cells than GRP, CALR, or ENK cells in the WT mouse $\left(F_{(3,29)}=20.2, p<0.001\right)$. Also, there is a significantly greater number of appositions of GRP onto CALR neurons $\left(F_{(2,23)}=6.2, p=0.008\right)$ compared to AVP neurons, although this statistical difference did not hold for GRP onto VIP. In contrast, VIP, ENK, and CALR cells make a similar number of appositions with the other cell types.

Unlike the WT mouse, there were no significant differences in reciprocal connections between GRP and AVP and CALR cell types in the VIP-KO mouse. Comparison of WT and VIP-KO in number of neurons receiving appositions from other neuronal cell types yielded no significant differences between strains (Table 3).

\section{Effect of VIP-KO on AVP}

When examining appositions, we noted that, compared to WT mice, AVP expression was reduced in the SCN neurons of VIP-KO mice, with no differences between groups in the size of SCN AVP cells (WT: $84.2 \pm 1.6 \mu \mathrm{m}^{2}$; VIP-KO: $\left.86.7 \pm 2.3 \mu \mathrm{m}^{2}, t_{(133)}=0.88, p=0.38\right)$. There-

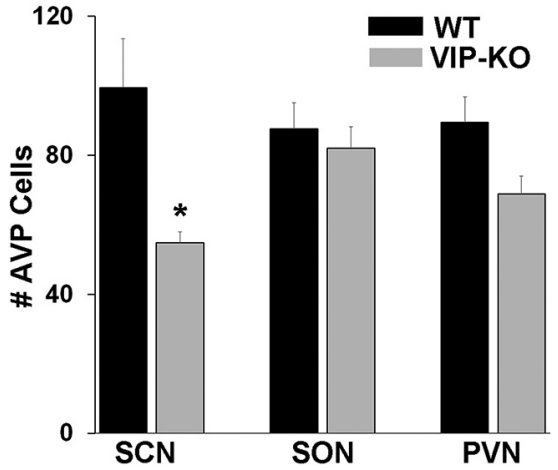

Figure 6. Numbers of AVP neurons in SCN, SON and PVN of WT and VIP-KO mice. In VIP-KO, the number of AVP-ir neurons is significantly lower in the SCN, but not in SON or PVN compared to WT littermates; $* p<0.001$ versus WT.

fore, AVP expression in littermates of the WT and VIP-KO mouse were compared. Examination of coronal and sagittal sections indicates that the expression of AVP in the VIP-KO mouse is severely reduced in the SCN. This can be seen throughout the extent of the nucleus in photomicrographs of sections stained for AVP (Fig. 5). Comparison of the number of AVP neurons in SCN, SON and PVN indicates that the reduction in AVP-ir cell number is restricted to the SCN and is not seen in SON and PVN, nearby AVP-rich regions (ANOVA: WT vs VIP-KO: $F_{(1,33)}=$ $11.3, p=0.002$; brain regions $F_{(2,33)}=0.46, p=0.63$; interaction $F_{(2,33)}=2.8, p=0,08$; Fig. 6).

\section{AVP appositions onto other cell types, WT versus VIP-KO}

We were surprised to note that although VIP-KO mice had fewer AVP-ir neurons, the number of GRP, CALR and ENK neurons receiving more than or equal to three AVP 


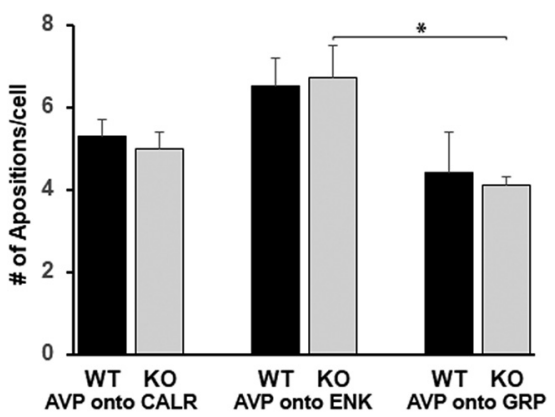

Figure 7. Quantification of number of appositions of AVP cells onto other peptidergic cell types in WT and VIP-KO mice (ANOVA: WT vs VIP-KO: $F_{(1,30)}=0.07, p=0.79$; peptidergic cell type $F_{(2,30)}=7.94, p=0.002$; interaction $F_{(2,30)}=0.45, p=$ 0.89). * Tukey test: $p=0.01$.

appositions did not differ between WT and VIP-KO mice. To reassess this surprising result, we revisited the finding by analyzing the absolute number of appositions made by AVP cells onto ENK, GRP, and CALR cells in WT and VIP-KO littermates (Fig. 7; Table 4). Here again, there were no differences between WT and VIP-KO mice in number of AVP appositions made on each peptidergic type.

\section{Number of AVP neurons in SCN of colchicine- treated VIP-KO mice}

The assessment of appositions indicated similar numbers of contacts between AVP and other neurons in the
VIP-KO and WT animals, although we saw fewer AVP neurons in the VIP-KO. We sought to assess whether this was the result of fewer AVP neurons making more contacts, or a similar number of neurons in the two cell types but a reduction in detectable AVP peptide. To assess whether there is a decrease in numbers of neurons producing AVP in the mutant mice or rather, a deficit in AVP synthesis, the number of AVP neurons in colchicinetreated VIP-KO mice and WT littermates were compared ( $N=6$ /group; Fig. 8). The results indicate that there was no significant difference in the number of AVP neurons in the SCN of WT and colchicine-treated VIP-KO littermate mice.

\section{Colocalization of peptides in WT and VIP-KO}

We next asked whether VIP-KO and WT mice differed in colocalization of major SCN peptides. In WT mice, there was colocalization of CALR with AVP, VIP, and GRP (Fig. 9). There was no colocalization detected of other peptides (AVP/GRP, AVP/VIP, VIP/GRP AND ENK/AVP, ENK/GRP, ENK/VIP, or ENK/CALR; data not shown). Finally, there were no differences between WT and VIP-KO littermates in colocalization of peptides (Fig. 10; Table 5).

\section{Discussion}

\section{Appositions between SCN neurons}

Although individual neurons are oscillators, it is widely agreed that the network of the SCN is essential for normal

Table 4. Comparison of WT and VIP-KO mice: number of AVP appositions/cell onto CALR, ENK, and GRP cell types

\begin{tabular}{|c|c|c|c|c|}
\hline Cell type & \# appositions/cell (mean \pm SEM) & \# cells & \# animals & Tukey test WT vs VIP-KO \\
\hline AVP to CALR-WT & $5.3 \pm 0.4$ & 222 & 6 & $p=0.73$ \\
\hline AVP to CALR-KO & $5.0 \pm 0.4$ & 189 & 6 & \\
\hline AVP to ENK-WT & $6.5 \pm 0.7$ & 121 & 5 & $p=0.80$ \\
\hline AVP to ENK-KO & $6.7 \pm 0.8$ & 178 & 5 & \\
\hline AVP to GRP-WT & $4.4 \pm 1.0$ & 70 & 4 & $p=0.70$ \\
\hline AVP to GRP-KO & $4.1 \pm 0.2$ & 68 & 5 & \\
\hline
\end{tabular}
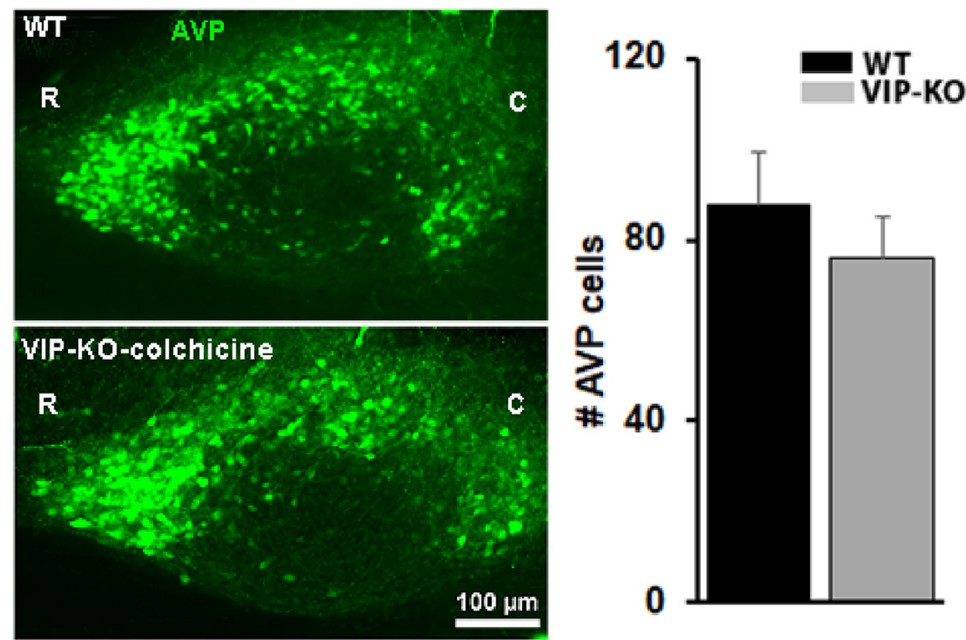

Figure 8. Left panels: Photomicrographs depict AVP in SCN of WT and VIP-KO colchicine-treated littermates (R, rostral; C, caudal). Each pair of animals (WT and VIP-KO-colchicine) was tested in the same experimental runs. Right panels: Number of AVP cells in WT and VIP-KO colchicine treated mice $\left(t_{(10)}=0.82, p=0.43\right)$. 


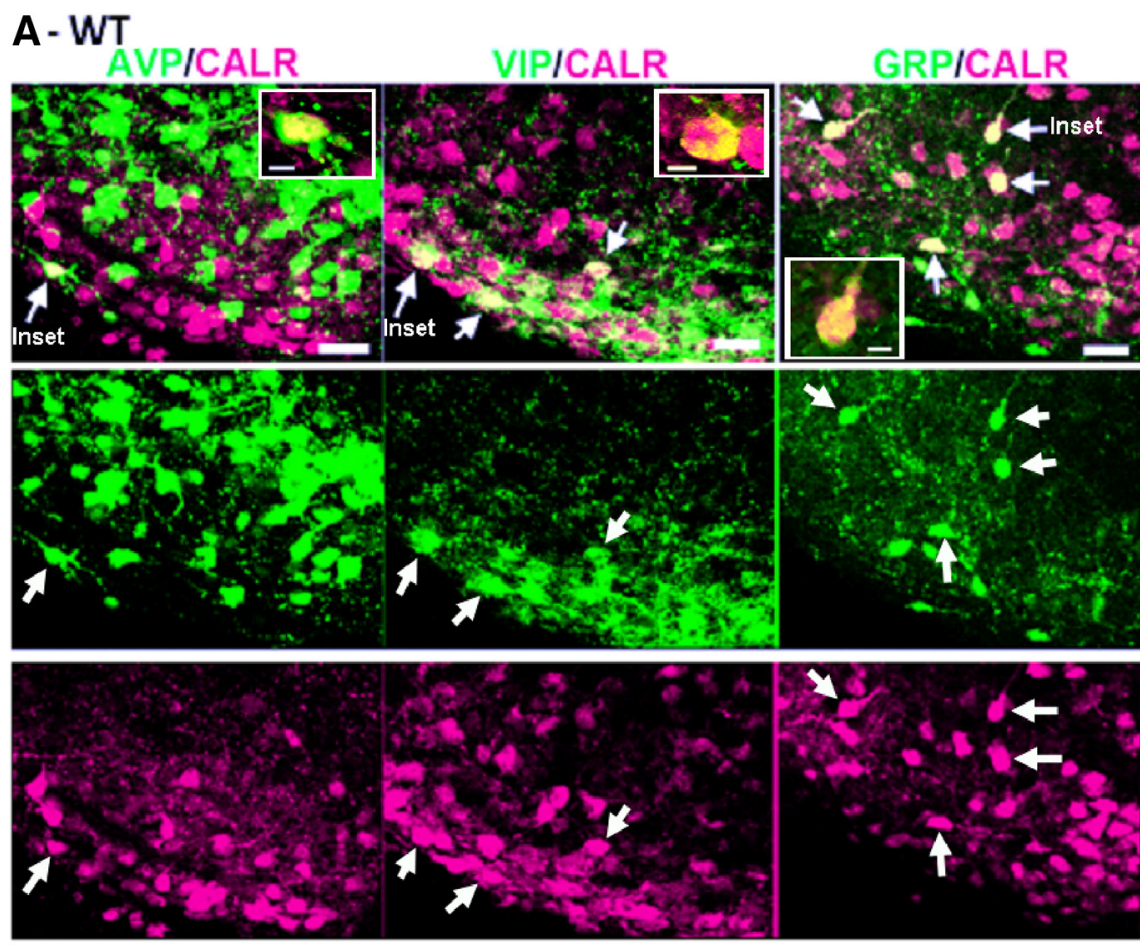

B - KO
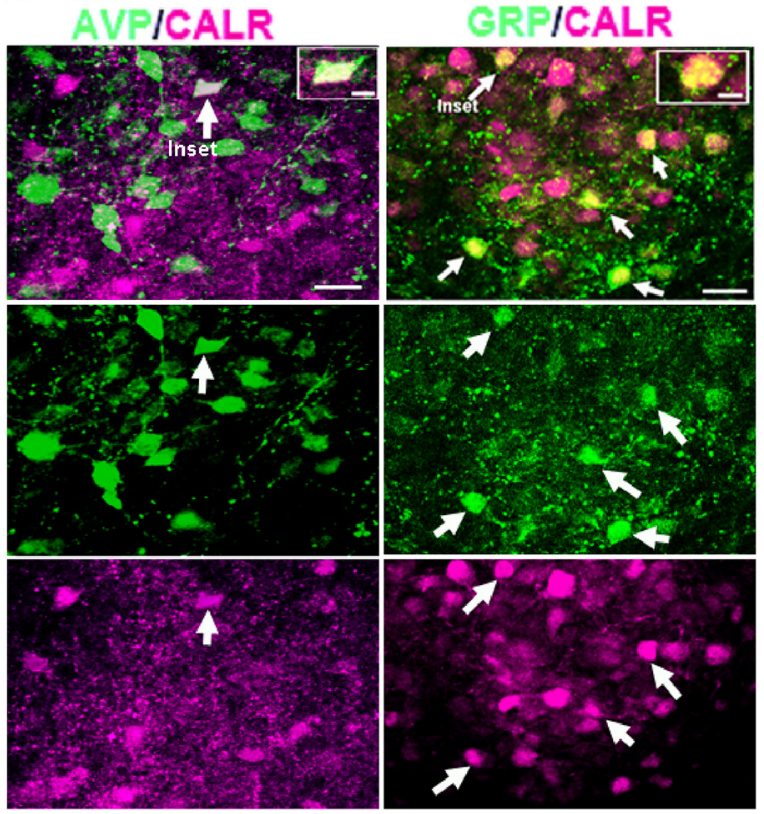

Figure 9. Confocal photomicrographs of sagittal SCN sections from WT $(\boldsymbol{A})$ or VIP-KO $(\boldsymbol{B})$ mouse stained for AVP, CALR, VIP, and GRP, as indicated. The merged channels are shown in the upper rows and each separate channel is shown in the middle and third rows $(z$-axis $=3 \mu \mathrm{m}$, scale bar $=20 \mu \mathrm{m})$. The arrows point to double-labeled cells, In each panel in the merged channel, the cell shown in the inset is also identified (insets: $z$-axis $=1 \mu \mathrm{m}$; scale bar $=5 \mu \mathrm{m}$ ).

circadian timekeeping (Hastings et al., 2014; Pauls et al., 2016; Herzog et al., 2017). This study addressed a caveat in that much of the data on which this consensus rests derives from studies of mice, but evidence on the nature of connections among SCN neurons derives from rats and/or hamsters. The general notion is that in rodents, core neurons communicate with those in the shell while there is less communication in the reverse direction (Leak et al., 1999). The present study explores appositions between various core and shell peptidergic cell types in the mouse SCN. The results suggest that while approximately equal, reciprocal appositions occur between some neurons examined, impressively, this was not the case for other, major core-shell connections. Specifically, for AVP to VIP, fewer than $10 \%$ of VIP neurons received more than or equal to three AVP contacts, while for VIP to AVP, $90 \%$ 


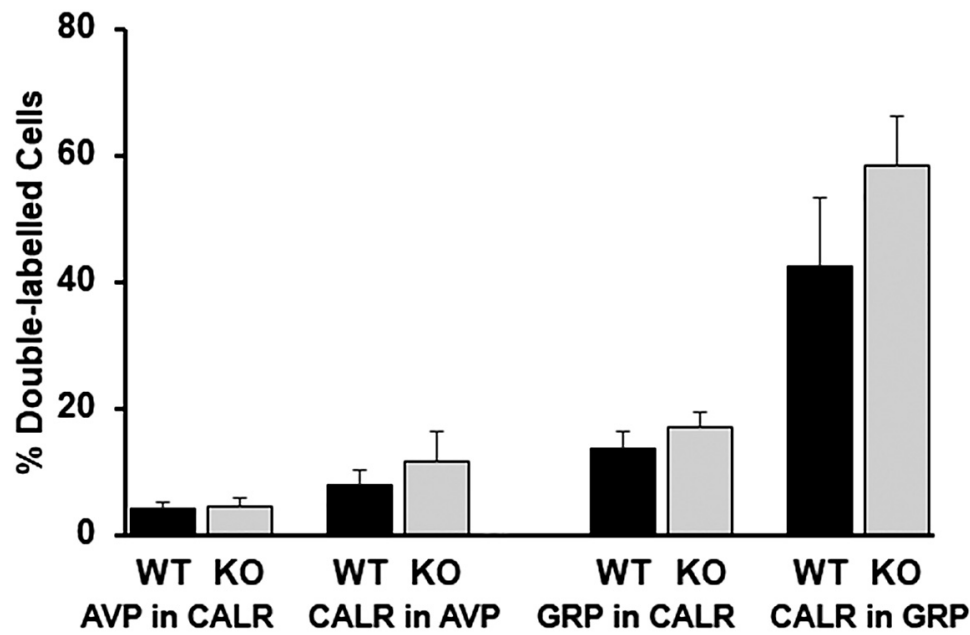

Figure 10. Colocalization of peptides in WT and VIP-KO mice. No differences were detected between genotypes. See Table 5 for statistics.

of AVP neurons received more than or equal to three VIP contacts. Some differential communication among core neurons was also detected, with GRP making more appositions onto CalR than onto VIP or AVP neurons.

We also found that in contrast to their WT littermates, there was a marked reduction in number of detectable AVP neurons in VIP-KO mice, although a few intensely labeled neurons were seen in each animal. Surprisingly, these mice had the same numbers of appositions as WT mice. We assessed whether this could be due to sprouting of fibers as a consequence of the reduction in neuron number in these mice. However, when transport of AVP was blocked by administration of colchicine in VIP-KO mice, the numbers of AVP neurons were comparable to WT animals. Such results are consistent with reduction of AVP synthesis and/or asynchronous AVP rhythms in the VIP-KO mice and with findings that VIP regulates the long-term firing rate of SCN neurons (Kudo et al., 2013)

\section{The SCN connectome}

The results of this study clarify core to shell communication in the mouse SCN and reexamine the general hypothesis put forth in previous work that the communication from core to shell is more extensive than the reverse (Daikoku et al., 1992; Leak et al., 1999). The results indicate that this general pattern does not apply to all neuronal subtypes of the core. More specifically, we find that there are far more contacts made by VIP core neurons onto AVP shell neurons than the converse. There was also evidence of specialization in that the core GRP neurons receive more appositions from AVP neurons than the converse. Unexpected was the trend suggesting that essentially all CalR neurons receive appositions from GRP, but there are fewer contacts in the reverse direction. Such results suggest important specializations of the network. The same general pattern of core to shell and intracore connections is seen in other species, with differences in the specific peptides involved. In hamster, CalB neurons receive numerous appositions from VIP and GRP fibers (LeSauter et al., 2002). Reciprocal connections are seen between VIP and GRP neurons in hamsters and in rats (Romijn et al., 1997). It is clear from numerous studies that for AVP-to-VIP connections, AVP fibers are much more densely distributed in the AVP-rich shell area than in the VIP and GRP-rich core areas both in rats and in mice (van den Pol, 1986; Daikoku et al., 1992; Abrahamson and Moore, 2001; Moore et al., 2002). In close agreement with the present results, Jacomy et al. (1999) show that around $80 \%$ of VIP cells received few AVP appositions. With regard to the present results, we note that this work does not specify whether all appositions reported here originate from cells local to the SCN as cross talk between the bilateral SCN (Michel et al., 2013) or input from other brain regions may also occur.

Temporal variation of peptide expression complicates the task of defining the SCN connectome. Expression levels of some SCN peptides are under circadian regulation, with possible species differences in times of peak

Table 5. Comparison of WT and VIP-KO: \% neurons colocalizing AVP, CALR, GRP

\begin{tabular}{|c|c|c|c|c|c|c|c|c|}
\hline Colocalization & WT $(\%$ cells \pm SEM $)$ & \# cells & \# animals & $\mathrm{KO}(\%$ cells $\pm \mathrm{SEM})$ & \# cells & \# animals & $t$ test & $p$ value \\
\hline AVP in CALR & $4.1 \pm 1.0$ & 1060 & 12 & $4.4 \pm 1.3$ & 750 & 8 & $t_{(18)}=0.21$ & 0.83 \\
\hline CALR in AVP & $8.0 \pm 2.3$ & 879 & 12 & $11.6 \pm 4.7$ & 579 & 8 & $\begin{array}{l}t_{(18)}=0.75 * \\
T_{(8,12)}=88\end{array}$ & $\begin{array}{l}0.46 \\
0.79\end{array}$ \\
\hline GRP in CALR & $13.6 \pm 2.9$ & 1123 & 10 & $16.9 \pm 2.4$ & 831 & 8 & $t_{(16)}^{(0,12)}=0.83$ & 0.42 \\
\hline CALR in GRP & $42.6 \pm 10.7$ & 290 & 10 & $58.3 \pm 7.9$ & 256 & 8 & $t_{(16)}=1.12$ & 0.28 \\
\hline VIP in CALR & $6.9 \pm 1.8$ & 988 & 8 & & & & & \\
\hline CALR in VIP & $15 \pm 1.8$ & 307 & 8 & & & & & \\
\hline
\end{tabular}

* Normality failed, Mann-Whitney rank test $(T)$ is shown. 
expression among peptides. Circadian trafficking of calcium binding proteins in fibers of SCN neurons has been demonstrated in hamster (LeSauter et al., 2009) and rat (Moore, 2016). AVP receptor expression and AVP, VIP and GRP content in the SCN are rhythmic (Okamoto et al., 1991; Inouye and Shibata, 1994; Kalsbeek et al., 2010).

\section{VIP regulation of AVP}

Our observation that AVP protein is reduced in VIP-KO mice is consistent with previous related reports. VPAC2 is found in nearly all SCN cells, including AVP-containing cells (An et al., 2012). AVP mRNA is reduced in VPAC2-KO mice (Harmar et al., 2002) and AVP is induced by VIP or VPAC2 agonist (Rusnak et al., 2007). We had been surprised to note that the number of AVP appositions on other neurons did not differ between VIP-KO and WT mice. Given the finding that in colchicine-treated VIP-KO mice the number of AVP neurons was similar to their WT littermates, it appears that the VIP-KO mice have a reduction in AVP protein synthesis, but the amount of the peptide produced is sufficient to be detected with the present protocols.

\section{VIP-KO alters other genes and proteins}

It appears that the altered capability of VIP-KO and VPAC2-KO mice ability to express rhythmic behavioral responses is due in part to disruption of normal signaling not only of VIP but also of AVP. AVP not only augments the amplitude of rhythms within SCN but also acts as an output signal to the rest of the brain. There is a circadian rhythm of AVP in the cerebrospinal fluid (Schwartz and Reppert, 1985). AVP, acting through its V1 receptor, is important in augmenting electrical activity of SCN neurons (Ingram et al., 1998). AVP participates in coordinating oscillations through the AVP V1a receptor which extend widely in the SCN, including both core and shell regions (Li et al., 2009). AVP input to SCN neurons may contribute to its synchronizing effect within the SCN (Ingram et al., 1998; Bittman, 2009; Li et al., 2009), and this is likely part of the mechanism whereby AVP influences locomotor rhythms (Cormier et al., 2015). In summary, we conclude that the well characterized arrhythmicity of mice lacking VIP or its receptor (Colwell et al., 2003; Brown et al., 2007; Hughes and Piggins, 2008) may be due in part to the disruption in AVP in these animals.

\section{Colocalization of peptides in the SCN is the rule and not an exception}

The present results indicate that VIP and CALR as well as GRP and CALR are coexpressed in some but not all SCN neurons. In rat, colocalization of VIP, PHI, and GRP in some but not all neurons have been reported (Okamura and Ibata, 1986; Kawamoto et al., 2003). In hamster analysis of colocalization of peptides shows that $91 \%$ of the substance P cells, $42 \%$ of the GRP cells and $60 \%$ of the VIP cells in the core coexpress CalB (LeSauter et al., 2002).

\section{The SCN is a dynamic network}

The work on appositions in the WT mouse indicates that the SCN network is highly specialized. While AVP contacts onto VIP neurons are very sparse, the numbers of contacts onto GRP neurons are somewhat augmented compared to communications in the reverse direction. For other neuronal types, the communications appear to be largely reciprocal. The connectome delineated here indicates that the peptidergic network in VIP-KO animals is similar to that of WT, although the VIP protein is absent. Furthermore, in VIP-KO animals, there is a deficit not only in the VIP protein, but also in AVP. The consequences of compromised VIP-ergic signaling in the SCN have been seen in altered behavioral, cellular, and intercellular circadian activity. The present study shows that AVP synthesis is also compromised in these $\mathrm{KO}$ mice. Taken together this study characterizes the SCN network in mouse and further highlights the interrelationship between VIP and AVP in maintaining circadian timekeeping.

\section{References}

Abrahamson EE, Moore RY (2001) Suprachiasmatic nucleus in the mouse: retinal innervation, intrinsic organization and efferent projections. Brain Res 916:172-191. CrossRef

An S, Tsai C, Ronecker J, Bayly A, Herzog ED (2012) Spatiotemporal distribution of vasoactive intestinal polypeptide receptor 2 in mouse suprachiasmatic nucleus. J Comp Neurol 520:2730-2741. CrossRef

Antle MC, Silver R (2005) Orchestrating time: arrangements of the brain circadian clock. Trends Neurosci 28:145-151. CrossRef Medline

Aton SJ, Colwell CS, Harmar AJ, Waschek J, Herzog ED (2005) Vasoactive intestinal polypeptide mediates circadian rhythmicity and synchrony in mammalian clock neurons. Nat Neurosci 8:476483. CrossRef

Bittman EL (2009) Vasopressin: more than just an output of the circadian pacemaker? Focus on "Vasopressin receptor V1a regulates circadian rhythms of locomotor activity and expression of clock-controlled genes in the suprachiasmatic nuclei." Am J Physiol Regul Integr Comp Physiol 296:R821-R823. CrossRef

Brown TM, Colwell CS, Waschek JA, Piggins HD (2007) Disrupted neuronal activity rhythms in the suprachiasmatic nuclei of vasoactive intestinal polypeptide-deficient mice. J Neurophysiol 97:25532558. CrossRef

Buijink MR, Almog A, Wit CB, Roethler O, Olde Engberink AH, Meijer $\mathrm{JH}$, Garlaschelli D, Rohling JH, Michel S (2016) Evidence for weakened intercellular coupling in the mammalian circadian clock under long photoperiod. PLoS One 11:e0168954. CrossRef

Cagampang FR, Sheward WJ, Harmar AJ, Piggins HD, Coen CW (1998) Circadian changes in the expression of vasoactive intestinal peptide 2 receptor mRNA in the rat suprachiasmatic nuclei. Brain Res Mol Brain Res 54:108-112. CrossRef

Colwell CS, Michel S, Itri J, Rodriguez W, Tam J, Lelievre V, Hu Z, Liu X, Waschek JA (2003) Disrupted circadian rhythms in VIP- and PHI-deficient mice. Am J Physiol Regul Integr Comp Physiol 285: R939-R949. CrossRef Medline

Cormier HC, Della-Maggiore V, Karatsoreos IN, Koletar MM, Ralph MR (2015) Suprachiasmatic vasopressin and the circadian regulation of voluntary locomotor behavior. Eur J Neurosci 41:79-88. CrossRef

Daikoku S, Hisano S, Kagotani Y (1992) Neuronal associations in the rat suprachiasmatic nucleus demonstrated by immunoelectron microscopy. J Comp Neurol 325:559-571. CrossRef

Drouyer E, LeSauter J, Hernandez AL, Silver R (2010) Specializations of gastrin-releasing peptide cells of the mouse suprachiasmatic nucleus. J Comp Neurol 518:1249-1263. CrossRef

Güldner FH (1976) Synaptology of the rat suprachiasmatic nucleus. Cell Tissue Res 165:509-544. Medline 
Güldner FH (1983) Numbers of neurons and astroglial cells in the suprachiasmatic nucleus of male and female rats. Exp Brain Res 50:373-376.

Güldner FH (1984) Suprachiasmatic nucleus: numbers of synaptic appositions and various types of synapses. Cell Tissue Res 235: 449-452. Medline

Harmar AJ, Marston HM, Shen S, Spratt C, West KM, Sheward WJ, Morrison CF, Dorin JR, Piggins HD, Reubi JC, Kelly JS, Maywood ES, Hastings MH (2002) The VPAC(2) receptor is essential for circadian function in the mouse suprachiasmatic nuclei. Cell 109: 497-508. CrossRef

Hastings MH, Brancaccio M, Maywood ES (2014) Circadian pacemaking in cells and circuits of the suprachiasmatic nucleus. $J$ Neuroendocrinol 26:2-10. CrossRef Medline

Hazlerigg DG, Ebling FJ, Johnston JD (2005) Photoperiod differentially regulates gene expression rhythms in the rostral and caudal SCN. Curr Biol 15:R449-R450. CrossRef

Herzog ED, Hermanstyne T, Smyllie NJ, Hastings MH (2017) Regulating the suprachiasmatic nucleus (SCN) circadian clockwork: interplay between cell-autonomous and circuit-level mechanisms. Cold Spring Harb Perspect Biol 9. CrossRef

Hughes AT, Piggins HD (2008) Behavioral responses of Vipr2-/- mice to light. J Biol Rhythms 23:211-219. CrossRef Medline

Ibata Y, Tanaka M, Ichitani Y, Takahashi Y, Okamura H (1993) Neuronal interaction between VIP and vasopressin neurones in the rat suprachiasmatic nucleus. NeuroReport 4:128-130. Medline

Ingram CD, Ciobanu R, Coculescu IL, Tanasescu R, Coculescu M, Mihai R (1998) Vasopressin neurotransmission and the control of circadian rhythms in the suprachiasmatic nucleus. Prog Brain Res 119:351-364

Inouye ST, Shibata S (1994) Neurochemical organization of circadian rhythm in the suprachiasmatic nucleus. Neurosci Res 20:109-130. Medline

Jacomy H, Burlet A, Bosler O (1999) Vasoactive intestinal peptide neurons as synaptic targets for vasopressin neurons in the suprachiasmatic nucleus. Double-label immunocytochemical demonstration in the rat. Neuroscience 88:859-870. CrossRef

Kalsbeek A, Fliers E, Hofman MA, Swaab DF, Buijs RM (2010) Vasopressin and the output of the hypothalamic biological clock. $J$ Neuroendocrinol 22:362-372. CrossRef Medline

Kawamoto K, Nagano M, Kanda F, Chihara K, Shigeyoshi Y, Okamura H (2003) Two types of VIP neuronal components in rat suprachiasmatic nucleus. J Neurosci Res 74:852-857. CrossRef Medline

Klein DC, Moore RY, Reppert SM, eds (1991) Suprachiasmatic nucleus. The mind's clock. New York: Oxford University Press.

Kriegsfeld LJ, Leak RK, Yackulic CB, LeSauter J, Silver R (2004) Organization of suprachiasmatic nucleus projections in Syrian hamsters (Mesocricetus auratus): an anterograde and retrograde analysis. J Comp Neurol 468:361-379. CrossRef

Kudo T, Tahara Y, Gamble KL, McMahon DG, Block GD, Colwell CS (2013) Vasoactive intestinal peptide produces long-lasting changes in neural activity in the suprachiasmatic nucleus. J Neurophysiol 110:1097-1106. CrossRef

Leak RK, Card JP, Moore RY (1999) Suprachiasmatic pacemaker organization analyzed by viral transynaptic transport. Brain Res 819:23-32. CrossRef

LeSauter J, Kriegsfeld LJ, Hon J, Silver R (2002) Calbindin-D(28K) cells selectively contact intra-SCN neurons. Neuroscience 111: 575-585. CrossRef

LeSauter J, Bhuiyan T, Shimazoe T, Silver R (2009) Circadian trafficking of calbindin-ir in fibers of SCN neurons. J Biol Rhythms 24:488-496. CrossRef Medline

Li JD, Burton KJ, Zhang C, Hu SB, Zhou QY (2009) Vasopressin receptor $\mathrm{V} 1$ a regulates circadian rhythms of locomotor activity and expression of clock-controlled genes in the suprachiasmatic nuclei. Am J Physiol Regul Integr Comp Physiol 296:R824-R830. CrossRef

Maywood ES, Reddy AB, Wong GK, O’Neill JS, O'Brien JA, McMahon DG, Harmar AJ, Okamura H, Hastings MH (2006) Synchroni- zation and maintenance of timekeeping in suprachiasmatic circadian clock cells by neuropeptidergic signaling. Curr Biol 16: 599-605. CrossRef

Maywood ES, Chesham JE, O'Brien JA, Hastings MH (2011) A diversity of paracrine signals sustains molecular circadian cycling in suprachiasmatic nucleus circuits. Proc Natl Acad Sci USA 108: 14306-14311. CrossRef

Michel S, Marek R, Vanderleest HT, Vansteensel MJ, Schwartz WJ, Colwell CS, Meijer JH (2013) Mechanism of bilateral communication in the suprachiasmatic nucleus. Eur J Neurosci 37:964-971. CrossRef

Moore RY, Bernstein ME (1989) Synaptogenesis in the rat suprachiasmatic nucleus demonstrated by electron microscopy and synapsin 1 immunoreactivity. J Neurosci 9:2151-2162. Medline

Moore RY, Speh JC, Leak RK (2002) Suprachiasmatic nucleus organization. Cell Tissue Res 309:89-98. CrossRef Medline

Moore RY (2016) Calretinin neurons in the rat suprachiasmatic nucleus. J Biol Rhythms 31:406-410. CrossRef Medline

Okamoto S, Okamura H, Miyake M, Takahashi Y, Takagi S, Akagi Y, Fukui K, Okamoto H, Ibata Y (1991) A diurnal variation of vasoactive intestinal peptide (VIP) mRNA under a daily light-dark cycle in the rat suprachiasmatic nucleus. Histochemistry 95:525-528. CrossRef

Okamura H, Ibata $Y$ (1986) Distribution of VIP/PHI in the central nervous system (Japanese). Seitaino Kagaku 37:197-200.

Pauls SD, Honma KI, Honma S, Silver R (2016) Deconstructing circadian rhythmicity with models and manipulations. Trends Neurosci 39:405-419. CrossRef Medline

Piggins HD, Cutler DJ (2003) The roles of vasoactive intestinal polypeptide in the mammalian circadian clock. J Endocrinol 177:7-15. CrossRef

Romijn HJ, Sluiter AA, Pool CW, Wortel J, Buijs RM (1997) Evidence from confocal fluorescence microscopy for a dense, reciprocal innervation between AVP-, somatostatin-, VIP/PHI-, GRP-, and VIP/PHI/GRP-immunoreactive neurons in the rat suprachiasmatic nucleus. Eur J Neurosci 9:2613-2623. CrossRef

Rusnak M, Toth ZE, House SB, Gainer H (2007) Depolarization and neurotransmitter regulation of vasopressin gene expression in the rat suprachiasmatic nucleus in vitro. J Neurosci 27:141-151. CrossRef

Schwartz WJ, Reppert SM (1985) Neural regulation of the circadian vasopressin rhythm in cerebrospinal fluid: a pre-eminent role for the suprachiasmatic nuclei. J Neurosci 5:2771-2778. CrossRef

Silver R, Sookhoo Al, LeSauter J, Stevens P, Jansen HT, Lehman MN (1999) Multiple regulatory elements result in regional specificity in circadian rhythms of neuropeptide expression in mouse SCN. Neuroreport 10:3165-3174. CrossRef

Sosniyenko S, Hut RA, Daan S, Sumová A (2009) Influence of photoperiod duration and light-dark transitions on entrainment of Per1 and Per2 gene and protein expression in subdivisions of the mouse suprachiasmatic nucleus. Eur J Neurosci 30:1802-1814. CrossRef

van den Pol AN (1980) The hypothalamic suprachiasmatic nucleus of rat: intrinsic anatomy. J Comp Neurol 191:661-702. CrossRef Medline

van den Pol AN, Tsujimoto KL (1985) Neurotransmitters of the hypothalamic suprachiasmatic nucleus: immunocytochemical analysis of 25 neuronal antigens. Neuroscience 15:1049-1086. CrossRef

van den Pol AN (1986) Gamma-aminobutyrate, gastrin releasing peptide, serotonin, somatostatin, and vasopressin: ultrastructural immunocytochemical localization in presynaptic axons in the suprachiasmatic nucleus. Neuroscience 17:643-659. CrossRef

van den Pol AN, Gorcs T (1986) Synaptic relationships between neurons containing vasopressin, gastrin-releasing peptide, vasoactive intestinal polypeptide, and glutamate decarboxylase immunoreactivity in the suprachiasmatic nucleus: dual ultrastructural immunocytochemistry with gold-substituted silver peroxidase. $J$ Comp Neurol 252:507-521. CrossRef 
Welsh DK, Takahashi JS, Kay SA (2010) Suprachiasmatic nucleus: cell autonomy and network properties. Annu Rev Physiol 72:551577. CrossRef Medline

Yan L, Karatsoreos I, LeSauter J, Welsh DK, Kay SA, Foley DK, Silver $R$ (2007) Exploring spatiotemporal organization of the SCN circuits clocks and rhythms. Cold Spring Harbor Symp Quant Biol 72:527541.

Yan L, Silver R (2008) Day-length encoding through tonic photic effects in the retinorecipient SCN region. Eur J Neurosci 28:21082115. CrossRef Medline 